\title{
A study on the subjectivity of female recreational sport participants' coaching experience: $Q$ methodological approach
}

\author{
Wangsung Myung ${ }^{1}$ \& Kwangho Park ${ }^{2 *}$ \\ ${ }^{1}$ Hanshin University \& ${ }^{2}$ Yonsei University
}

\begin{abstract}
[Purpose] The purpose of this study is to conduct a typological classification of female recreational sport participants' coaching experience. [Methods] Q methodology was conducted using 25 Q-samples and 25 P-samples. Data were analyzed using PQmethod software. [Results] Four types were categorized: communication and character-oriented (I), function and immersion-oriented (II), process and fun-oriented (III), and function and inclusion-oriented (IV). These types were re-categorized as 'non-functional value-oriented (I, III)' and 'functional value-oriented (II, IV)'. [Conclusions] This study also made efforts to explore the value and norm that female participants expect from sport participation, which provided a variety of perspectives on social, psychological and philosophical discussions about woman sport. In addition, each type and its characteristics can be used as meaningful basic data in teaching method (coaching theory) for woman sport.
\end{abstract}

Key words: Recreational sport, Woman sport, Coaching, Subjectivity, Q methodology

\section{서 론}

그동안 스포츠와 여성의 관계는 국내외 학계(체육학, 교 육학, 여성학), 정책입안자, 실무자 등에 의해 광범위하게 논의되어왔다. 주로 여성의 스포츠 참여 제약요인과 참여 촉진방안을 탐색하는데 많은 노력을 기울였다. 그 배경에는 '여성이 남성에 비해 스포츠 참여 빈도가 낮음'을 보여주는 정량적 자료와 그에 따른 문제의식에 기반하고 있다. 실제 로 남녀 간 스포츠 참여 비율을 비교한 다수의 분석 사례들 은 이러한 사실을 뒷받침한다.

Sport England(2017)에 따르면, 영국 남성 중 40.5\%는 일주일에 한 번 이상 스포츠에 참여하는 반면 여성은 $31.9 \%$

논문 투고일 : 2020. 07. 31 .

논문 수정일 : 2020. 09. 29.

게재 확정일 : 2020. 10. 13.

* 교신저자 : 박광호(pkh0977@gmail.com).

* 이 논문는 2019년 대한민국 교육부와 한국연구재단의 지원을 받아 수행된 연구임(NRF-2019S1A5B5A07109692).
로 상대적으로 낮게 나타났다. 조사가 시행된 이후 그 격차 는 눈에 띄게 줄어들고 있으나 여전히 유의미한 차이를 보이 고 있다. 스페인 청소년을 대상으로 진행된 한 연구 (Gomez-Baya, Mendoza \& Tomico, 2018)에서도 여성 의 스포츠 참여율은 현저히 낮게 보고되었다. 그들은 스포 츠 참여 빈도를 '매일(남=28.8\%, 여=8.6\%)', '일주일 한 번 이상(남 $=51.3 \%$, 여=37\%)'으로 구분했는데 두 영역 모두 남 녀 간 참여율에 상당한 차이를 보이고 있다. 반면, '전혀 안 함(남=8.3\%, 여=16.3\%)', '거의 안함(남=8\%, 여=24.9\%)' 과 같은 부정 응답률은 여성이 약 2-3배 이상 높게 나타났 다. Youth Sport Trust(2000)는 약 40\%의 영국 여성들이 14 세에 스포츠 참여를 중단한다고 보고하기도 했다.

국외 사례뿐만 아니라 국내 정량적 자료 역시 모든 연령 대에서 여성의 스포츠 참여율이 남성보다 낮음을 보여준다. Ministry of Culture, Sports and Tourism(2017)이 실 시한 생활체육 참여실태 조사 결과, 여성의 $32.8 \%$ 가 최근 1 년간 체육활동을 전혀 하지 않은 것으로 나타난 반면 남성은 $24.9 \%$ 로 나타났다. 구체적으로 10 대(남=22.9\%, 여=38\%) 
와 20대(남=24.4\%, 여=36.1\%)에서 가장 큰 차이를 보였으 며, 연령대가 높을수록 그 차이가 감소하였다. 같은 기관에 서 조사한 2012년 자료와 비교하면, 10 대(남 $=46.5 \%$, 여 $=72.9 \%$ )와 20대(남 $=50 \%$, 여=67.3\%) 모두 전체적인 참여 율 증가는 물론 남녀 간 격차도 상당 부분 해소되었지만 그 격차는 여전히 크다(MCST, 2012). 이처럼 여성(특히, 여성 청소년)의 낮은 스포츠 참여율은 국외 사례와 동일한 현상 을 보이고 있다.

여기서 주목해볼 문제(issue)는 남녀 간 스포츠(생활체 육) 참여율의 불균형이 새로운 사회 문제로 재생산될 수 있 다는 점이다. 다수 선행연구들이 지적했던 운동부족으로 인 한 신체·정신적 질환(또는 신체활동이 주는 효과)은 차치하 더라도, 남녀 간 스포츠 참여의 불균형이 초래할 사회적 잠 재위험성 역시 주목할 필요가 있다. 이는 젠더뿐만 아니라 지역, 연령, 직업, 소득 등 다른 계층 간에도 동일하게 적용 된다. 이러한 주장은 스포츠가 단순히 게임기술과 규칙으로 형성된 일차원적 활동이 아닌 McIntyre가 제시한 '실천전 통(a practice)'이라는 관점에서 비롯된다(Choi, 2012). 여기서 실천전통이란 사회적으로 확립된 협동적인 인간 활 동의 모종의 일관되고 복잡한 형식이다(McIntyre, 1984). Choi(2012)는 "인간이 역사적, 사회적, 문화적으로 형성해 놓은 삶의 방식(p9)”으로 규정했으며, 그(실천전통) 안에는 다양한 가치들이 내재되어 있다고 하였다.

이런 관점에서 스포츠는 기능(수행)적 차원을 넘어 '문화 적으로 가치 있는 인간의 사회적 활동'으로 간주된다 (Arnold, 1997). 이 경우 남녀 간 스포츠 참여율의 불균형 문제는 단순히 신체 움직임에 그치지 않고 인간 문화로부터 의 소외라는 새로운 문제에 직면하게 된다. 다시 말해, 서두 에서 확인한 여성의 낮은 스포츠 참여율을 '신체·정신적 질 환'이라는 지배적 문제의식에서 벗어나 '사회·문화적 소외' 라는 새로운 관점으로 바라볼 필요가 있다는 것이다. 스포 츠라는 현대사회의 '실천전통'이 고루 분배되지 않고 특정 젠더 집단에 의해 독점된다면, 새로운 차원의 차별과 권력 의 수단으로 전락할 수 있다. 아쉽게도 국내 생활 및 엘리트 체육 현장(특히, 일선 행정가와 지도자의 남녀 분포)은 이러 한 우려로부터 자유롭지 못한 실정이다.

그렇다면 왜 여성은 남성보다 스포츠 참여율이 현저히 낮 은 것인가. 특히, 낮은 연령층에서 그 격차가 더욱 큰 이유는 무엇인가. 이에 대해 다수 연구자는 각기 다른 또는 유사한 답변을 내놓았다. 이를 종합해보면 첫째, 사회·문화적 장벽
이다. 스포츠는 남성의 활동이라는 지배적인 사회 신념 (Cockburn \& Clarke, 2002)과 스포츠가 여성성을 지지 해주지 않는다는 오해(Coakley \& White, 1992)가 대표적 이다. 이를 '여성스러움'이라는 젠더 고정관념으로도 이해 할 수 있다.

둘째, 심리적 장벽이다. Wigfield et al.(1997)는 구조화 된 스포츠가 여성의 자신감 부족을 유발하여 참여 의지를 감 소시킨다고 하였다. 여기서 중요한 점은 '구조화된 스포츠 (높은 진입장벽)'로, 여성이 남성보다 기술 수준이 낮다고 인식하는데 상당한 영향을 미친다. 이러한 실패의 경험과 자신감 부족은 스스로 마르고 탄력 있는 몸이 아니라고 느낄 때 더욱 뚜렷하게 나타난다(Lee et al., 1999).

셋째, 코치의 리더십 문제이다. 여기서 코치란 운동을 가 르치는 강사, 지도자, 교사 등을 포괄하며, 따라서 이들이 행 하는 강습, 훈련, 수업은 모두 코칭의 보통 명사로 이해할 수 있다(Choi, 2012). Institute of Youth Sport(2000)는 코 치의 지나친 경쟁 기회 제공과 포용성 부족을 지적하였다. 스포츠의 여러 속성 중 하나인 경쟁에만 집착한 프로그램이 여성의 참여를 감소시킨다는 것이다. 또한, 여성의 신체적 특수성이 반영되지 않은 연습 프로그램을 일방적으로 제공 하거나 참여자에게 비판적, 공격적 반응을 보이는 등 의사 소통의 문제도 있다(Garrett, 2004).

이외에도 법제도적 요인들(정책 및 법, 교육체계 등)이 존 재할 수 있으나, 스포츠 활동이 이루어지는 실제 현장(교수학습과정)에서는 위 세 가지 요인으로부터 크게 벗어나지 않는다. 그리고 본 연구는 이들 요인의 근원을 '코칭 행동' 으 로 규정했으며, 이러한 문제의식을 바탕으로 연구의 첫 걸 음을 내딛었다. 위에서 세 번째 요인으로 지적한 코치의 리 더십은 물론 사회문화적 장벽과 심리적 장벽 역시 코칭 행동 이 직접 영향을 미치거나 코칭 행동의 개선으로 극복할 수 있는 문제이기 때문이다.

예컨대, 체육교사의 왜곡된 젠더 고정관념은 여학생의 소극적 참여를 유발하는데(Cho \& Lim, 2012; Jeong, Ahn \& Shin, 2008), 이는 앞서 살펴본 사회문화적 장벽이 코칭 행동으로부터 야기된 대표적 사례이다. Park \& $\mathrm{Na}$ (2013)는 스포츠 세계에서 성차별의 양태를 연구한 결 과, 남성 지도자의 가부장적 이념 및 전형적인 여성성 강조 등 의사소통 문제를 지적하기도 했다. 역으로 Hong \& $\operatorname{Yim}$ (2018)의 연구는 지도자의 젠더중립적 태도가 여성의 스포츠 참여 특히, 성(性)과 상반된 젠더유형 스포츠로의 참 
여를 장려했다고 보고하였다. 이들 연구는 '코칭 행동'이 여 성의 스포츠 참여에 있어 사회문화적 장벽을 견고히 하거나 극복하는데 영향을 미치고 있음을 시사한다.

심리적 장벽에서 지적한 '구조화된 스포츠'는 그 대안적 콘텐츠로서 뉴스포츠의 개발 및 도입으로 극복할 수 있다. 근대스포츠(구조화된 스포츠)는 기술 중심(Lee \& Yu, 2010; You, 2007), 남성 지배 논리에 의한 소외(Kim, 2009; Kim, 2010) 등 여성의 스포츠 참여에 한계를 지니고 있는데 뉴스포츠가 그 대안이 될 수 있다는 것이다. $\operatorname{Kim}(2009)$ 은 혼성체육수업에서 뉴스포츠는 '참신', '만 족', '몰입', '이해', '간편’이라는 다섯 가지 긍정적 체험을 기대할 수 있다고 했다. 비슷한 연구(Kim \& Kim, 2014)에 서도 뉴스포츠가 운동능력이 낮은 여학생에게 '단순하고 평 등한 스포츠'로 인식되면서 적극적 참여를 유발한다고 하였 다. 이들 연구는 지도자의 '구조화된 스포츠'에 대한 문제의 식 및 행동 변화(뉴스포츠의 개발 및 적용과 같은 노력)가 여 성의 참여와 만족을 향상시킬 수 있음을 보여준다. 결국 거 시적 관점에서 법제도적 요인과 함께 스포츠 활동의 직접적 인 공급자, 즉 코치의 행동이 여성의 스포츠 참여에 상당한 영향을 미치고 있다.

이처럼 여성의 스포츠 참여 제약요인 및 촉진 방안을 논 의함에 있어 코칭 행동은 중요한 논제임에도 불구하고, 그 동안 국내 학계에서는 '코칭 행동'에 대한 수요자(여기서는 여성 참여자) 중심의 연구가 거의 이루어지지 못했다. 주로 연역적 접근을 통해 코칭 유형(리더십, 지식, 언어, 행동, 통 제전략)과 특정 변인(신뢰, 자신감, 경기력, 응집력, 동기, 만족, 탈진, 자아존중, 행복감) 간의 관계를 검증하는데 많 은 지적 관심이 기울여졌다(Cheon, 2011; Kim, 2012; Kim \& Park, 2016; Kim, Shin \& Kwon, 2014; Lee, 2018; Park, Kim \& Park, 2017; Song, Cheon \& Hwang, 2017; Yoo, Kim \& Hwang, 2017). 이들 연구는 대부분 학원 및 엘리트 스포츠 그리고 남성을 주요 대상으로 삼은 것이 특징이다. 최근에는 코칭 윤리(Park, 2018)와 함 께 기능중심에서 교육중심으로 코칭 패러다임의 변화를 논 의한 문헌연구들이 이어지고 있다(Cho, 2015, 2017; Choi, 2012).

따라서 본 연구는 그동안 상대적으로 주목받지 못했던, 그렇지만 사회문화적 소외 관점에서 논제 가치가 있는, 여 성 생활체육 참여자들의 코칭 경험에 대한 수용인식을 탐색 하는데 그 목적이 있다. 여기서 수용인식이란 참여자들이
스포츠 참여 시 지도자로부터 제공받은 코칭에 대한 심리적 반응이다. 다수 선행연구들이 채택했던 이론적 가설을 검증 하는 연역적 접근 방식과 달리, 참여자들의 코칭 체험을 내 재적 관점에서 살펴보기 위함이다. 구체적으로 $\mathrm{Q}$ 방법론을 분석 틀로 차용하여 코칭 경험에 관한 여성 참여자들의 심리 적 주관성을 유형화하고, 각 유형의 특징을 파악하는데 초 점화된 연구를 진행한다. 이를 통해 참여자의 자아구조 내 코칭 행동에 대한 수용인식과 선호유형을 규명함으로써 전 통 방법론의 한계를 극복할 수 있을 것으로 기대한다. 이는 여성 생활체육 참여자들의 참여 제약요인 및 참여 촉진방 안, 그리고 코칭 행동의 취약점을 보완할 수 있는 의미 있는 작업이 될 수 있다. 더 나아가 Q방법론이 지닌 발견적 추론 의 특성과 학술적 유용성을 제고하는 데에도 기여할 수 있을 것이다.

연구 목적을 달성하기 위한 구체적인 연구 문제는 다음과 같다. 첫째, 여성 생활체육 참여자가 수용한 코칭 행동의 선 호유형을 탐색한다. 둘째, 각 유형별 특징을 살펴본다. 셋 째, 각 유형별 학술적 또는 실용적 의의를 도출한다.

\section{연구방법}

본 연구는 여성 생활체육 참여자들의 코칭 경험에 대 한 수용인식을 유형화하는데 그 목적이 있다. 이는 개인 의 심리적 주관성에 의존하는 것이며 가설 검증이 아닌 가설 발견(추론)에 근접한 방식이다. $\mathrm{Q}$ 방법론은 이러한 연구 목적을 달성하는데 유용한 분석 틀을 제공한다. Stephenson(1953)에 의해 개발된 Q방법론은 간호학, 광고학, 심리학, 사회학, 교육학, 체육학 등 인간을 대상 으로 하는 학문 분야로부터 큰 관심을 받아왔다. 국내에 서는 $\operatorname{Kim}(1992,2008)$ 과 Korean Society for the Science Study of Subjectivity(2002, 2014)가 선도하 고 있다.

$\mathrm{Q}$ 방법론은 관찰 가능한 현상을 외부로부터 설명하기 보 다는 특정 현상(또는 체험)에 대한 참여자의 내부 관점(감 정, 견해, 가치 등)으로부터 유형화된 주관성 구조를 파악하 는, 즉 내재적 접근 방식을 취한다. 특히, 연구자가 사전에 조작한 가설 모형을 검증하는 연역적 방법과 달리 참여자가 지각적 판단을 통해 스스로 $\mathrm{Q}$-표본을 조작하기 때문에 해 석적이라고 할 수 있다. 이는 그동안 과소평가되었던 개인 
Table 1. Q-statement

\begin{tabular}{|c|c|}
\hline No. & Q-statement \\
\hline 1 & $\begin{array}{l}\text { My coach offers a differentiated program for each individual } \\
\text { level. }\end{array}$ \\
\hline 2 & My coach is excellent in team mediation ability. \\
\hline 3 & My coach is full of passion when coaching. \\
\hline 4 & My coach distinguishes the roles of male and female. \\
\hline 5 & My coach sets plans and goals with participants. \\
\hline 6 & My coach emphasizes theory as much as skill. \\
\hline 7 & My coach values the process more than the result. \\
\hline 8 & My coach makes an effort for interest. \\
\hline 9 & $\begin{array}{l}\text { My coach directs the humanistic activities related to the } \\
\text { practice. }\end{array}$ \\
\hline 10 & My coach utilizes humanistic resources related to the practice. \\
\hline 11 & My coach regards personality as much as skill. \\
\hline 12 & My coach often compliments me. \\
\hline 13 & My coach is soft in expression. \\
\hline 14 & $\begin{array}{l}\text { My coach teaches based on his own experience rather than } \\
\text { theory (science). }\end{array}$ \\
\hline 15 & My coach only evaluates the participants with their skills. \\
\hline 16 & My coach emphasizes personal development rather than team. \\
\hline 17 & $\begin{array}{l}\text { My coach is clear on compensation and punishment } \\
\text { depending on the result. }\end{array}$ \\
\hline 18 & $\begin{array}{l}\text { My coach often provides opportunities for interaction with } \\
\text { teammates. }\end{array}$ \\
\hline 19 & My coach avoids frequent feedback. \\
\hline 20 & My coach offers high difficulty and strength. \\
\hline 21 & My coach counsels personal anxieties. \\
\hline 22 & My coach keeps a certain distance from the participants. \\
\hline 23 & My coach regards improving skills as the most important. \\
\hline 24 & My coach demonstrates the motion directly. \\
\hline 25 & My coach points out my strengths and weaknesses. \\
\hline
\end{tabular}

의 주관성에 의미를 부여하게 해준다. 이처럼 $\mathrm{Q}$ 방법론은 새 로운 의미의 가설 생성과 관련 후속 연구를 위한 탐색적 기 능에 유용하다(Kim, 2008).

또한 Q방법론은 인간의 자아구조를 계량적으로 유형화 하기 위한 기법으로 양적 및 질적 연구방법의 속성을 동시에 지니고 있다(Mckweon \& Thomas, 2013). 그럼에도 Q방 법론이 질적 연구로 분류되는 결정적 이유는 분석 도구로서 연구자의 역할이 큰 비중을 차지하고 있기 때문이다. 실제
로 $\mathrm{Q}$ 방법론의 수행 절차는 총 네 단계 $(\mathrm{Q}-$ 표본 $\rightarrow \mathrm{P}-$ 표본 $\rightarrow$ $\mathrm{Q}-$ 분류 $\rightarrow \mathrm{Q}$-요인분석)로 이루어지는데 이 중 마지막 단계 인 Q-요인분석을 제외한 모든 단계에서 연구자의 개입이 발생한다.

이렇듯 $\mathrm{Q}$ 방법론의 특징과 유용성은 본 연구의 목적에 적 절한 분석 틀을 제공하고 있다. 특히, 인간 대상 연구에서의 실용성은 여성 생활체육 참여자의 주관적 의미를 탐색할 뿐 만 아니라 개인의 주관성 유형들이 어떻게 구조화되고, 각 유 형들이 어떤 의미를 지니고 있는지 살펴보는데 도움이 된다.

\section{Q-표본(Q-sample 또는 Q-statement)}

본 연구는 Q-표본을 추출하기 위해 문헌자료, 심층면 담, 개방형 질문지 등 다각적 자료수집방법을 활용하였다. 먼저, 스포츠 코칭 행동(유형)에 관한 자료를 국내외 선행 연구(학위논문 및 보고서 제외)로부터 수집 및 정리하였 다. 문헌자료는 정량 및 정성적 자료를 구분하지 않고 수 집하였으며, 주로 코칭 행동, 코칭 유형, 리더십 등과 관련 된 척도 개발 연구나 귀납적 분석 결과를 Q-표본 추출에 활용하였다(Avolio \& Bass, 2004; Bartho lomew, Ntoumanis \& Thogersen-Ntoum anis, 2010; Bass, 1985; Chelladurai \& Saleh, 1980; Choi, Choi \& Kim, 2011; Lacy \& Darst, 1985; Lee, 2016; Williams \& Deci, 1996).

다음으로 여성 생활체육 참여자 6명을 대상으로 심층면 담(경우에 따라, 개방형 질문지)을 실시하였다. 심층면담 대 상자의 선정 기준은 P-표본과 동일하게 적용하였다. 심층면 담은 반구조화된 면담으로 개인당 1 회씩 진행하였으며, 면 담 시간은 최소 30 분에서 최대 60 분이 소요되었다. 공통 질 문으로 스포츠 참여 현황 및 동기, 참여 촉진 및 제약요인, 코치(들)에 대한 소개, 코칭 유형과 방법, 코칭 경험에 관한 견해 및 그 이유, 개선 사항 등이다. 면담은 공통 질문을 중 심으로 진행하되 경우에 따라 자율적인 대화 형식을 적절히 병행하였다.

이러한 일련의 과정을 거쳐 의견 집합체(concourse)인 110 개(문헌=46, 심층면담=64)의 Q-모집단(Q-population) 을 1 차로 구성하였다. 이후 모집단에 대한 코딩 과정 및 내 용 타당도 검토를 거치면서 연구 목적에 적합하지 않거나 타 당도 오류가 의심되는 Q-표본을 제외하였다. 추가로 중복 또는 유사하다고 판단되는 Q-표본은 표본 간 통합 처리하 
였다. 최종적으로 총 25 개의 Q-표본을 선정하였으며, 이에 관한 자세한 내용은 〈Table 1>에 제시하였다.

\section{$\mathrm{P}$-표본(P-sample 또는 Q-sorter)}

$\mathrm{P}$-표본이란 의견 집합체에서 추출된 $\mathrm{Q}$-표본을 분류하 는 사람으로서 Q-sorter라고도 한다. Q방법론은 특정 변 인(또는 개인) 간 관계보다는 인간 내부의 심리적 주관성과 상대적 선호 성향의 차이를 규명하는 데 있으므로(Valenta \& Wigger, 1997), P-표본의 크기는 별다른 제한을 받지 않는다(Kim, 2008). 오히려 Watts \& Stenner(2005)는 표 본 크기가 클수록 개인의 주관성과 그 의미를 이해하는데 방 해가 된다고 하였다. 그러나 Q-분석 시 주성분 요인분석의 용이성을 감안하여 P-표본을 Q-표본의 크기 이상으로 선 정하는 것이 일반적 추세이다. 이에 본 연구는 연구 목적과 방법론을 고려하여 여성 생활체육 참여자 25 명을 $\mathrm{P}-$ 표본으 로 선정하였다.

참여자 선정 기준은 다음과 같다. 첫째, 여성 스포츠 참가 자로서 지도자로부터 코칭을 제공받는 자이다. 이는 지도자 의 도움 없이 개별적으로 참가하는 자를 미리 확인할 수 있 으며, 연구 목적인 코칭 경험에 대한 수용 인식을 살펴보는 데 필수 요건이다. 둘째, 스포츠 참여빈도가 최소 주 1 회 이 상인 자이다. 참여빈도가 낮거나 장기간 참여 경험이 없을 경우 자료수집에 제한이 있기 때문에 규칙적인 참가자를 선 별하였다. 셋째, 스포츠 종목에는 제한을 두지 않았다. 특정 종목 또는 지도자로 한정할 경우 참가자가 수용하는 코칭 경 험(결과)의 다양성을 확보하기 어렵다고 판단했기 때문이 다. 이에 본 연구는 각 유형별 $\mathrm{P}$-표본의 일반적 특성에 참여 종목을 제시함으로써 유형 해석과 논의에 반영하였다. P-표 본의 개인적 특성은 〈Table 4〉와 같다.

\section{Q-분류(Q-sort)}

$\mathrm{Q}$-분류는 앞서 선정된 $\mathrm{P}$-표본(응답자)이 Q-표본을 강 제 분류하는 것으로 요인분석을 위한 과정이다. 응답자들은 연구자로부터 제공받은 $\mathrm{Q}$-표본을 자세히 검토한 후 정규분 포형태로 고안된 Q-분류차트에 긍정, 중립, 부정 순으로 강 제 분류하였다. 구체적으로 25 개의 Q-표본을 개인의 선호 정도 $(-4,-3,-2,-1,0,+1,+2,+3,+4)$ 에 따라 〈Figure $1>$ 에 제시된 정규분포도에 표본 번호를 기재하였다. 1 차로 완성된 정규분포도에 대해 응답자 스스로 재검토 및 수정할
수 있는 기회를 제공한 후 최종적으로 Q-분류를 완성하였 다. 추가로 양극에 위치한 -4 과 +4 의 Q-표본에 대해서는 그 이유를 간략하게 서술하였으며, 이는 유형별 분석 시 활 용하기 위함이다.

\section{Q-요인분석(Q-analysis)}

본 연구는 Q-요인분석을 위해 PQmethod(ver.2.35) 소프트웨어를 활용하였다. PQmethod는 Q방법론 분석을 지원하는 소프트웨어 패키지 중 하나이다. Q-분석에 앞서 새로운 프로젝트를 생성하여 Q-표본과 Q-분류결과(분포 도)에 대한 코딩 작업을 진행하였다. 이후 베리맥스 회전을 활용한 주성분 요인분석(principle component factor analysis)을 실시하였으며, 요인 추출은 고유치 (eigenvalues) 1.0 이상을 기준으로 설정하였다. 통상적으 로 양적 연구방법에서의 요인분석은 측정문항 간 유사성을 확인 또는 탐색하지만 Q방법론은 Q-표본에 대한 응답자의 심리적 주관성을 유형(요인)화하는데 목적이 있다. 여기서 유형이란 성향(여기서는 코칭 경험에 대한 수용인식)이 비 슷한 P-표본의 집단을 의미하며, 각 유형의 특성은 표준점 수 \pm 1.0 이상인 Q-표본을 통해 해석 및 명명할 수 있다.

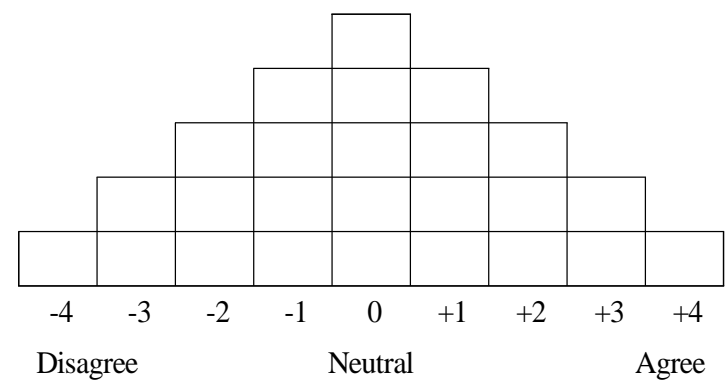

Fig. 1. Q-sort chart

\section{결과}

\section{유형 분석}

PQmethod를 활용한 Q-요인분석 결과, 여성 생활체육 참여자들의 코칭 경험에 관한 수용인식은 네 가지 유형으로 관찰되었다. 각 유형별 고유치를 살펴보면, 유형 I 이 11.10 
으로 가장 높게 나타났으며, 유형 I(2.91), 유형II(1.89), 유형IV(1.44) 순이다. 각 유형이 설명하는 변량은 유형 I 이 $27 \%$ 를 차지하고 있으며, 유형 II(17\%), 유형II(13\%), 유형 $\mathrm{IV}(13 \%)$ 순으로 나타났다. 그리고 이들 네 개 유형은 전체 변량 중 $70 \%$ 를 설명하고 있다.

각 유형 간 유사성 정도를 보여주는 상관계수는 유형 I 과 유형Iㅣㅇㅣ .623으로 가장 높게 나타났다. 반면 유형 I 과 유 형 $\mathrm{V}$ 의 상관계수는 .232 로 가장 낮게 나타나 상대적으로 독 립적이라고 볼 수 있다. 그러나 양적 연구와 달리 Q방법론 은 유형(변수) 간 다중공선성 문제로부터 자유롭기 때문에 상관계수에 큰 의미를 부여하지 않는다. 대신에 유형 간 상 관계수는 유형 해석 시 참고 자료로서 보다 활용 가치가 있 다. 예컨대, 본 연구에서 가장 높은 상관계수를 보이는 유형 I 과 유형Iㅣ은 ‘참여자 중심'이라는 공통점을 공유하고 있 다. 그 다음으로 높은 상관성을 나타내는 유형 $\Pi$ 와 유형 $\mathrm{V}$ 는 '참여자 중심'보다는 '기능 향상'에 보다 큰 의미를 두고 있
다. 이처럼 Q방법론에서 유형 간 상관계수는 유형 해석 시 정량적 수치와 객관적 정보를 제공한다. 유형별 고유치 및 변량은 〈Table 2〉, 유형 간 상관계수는 〈Table 3〉과 같다.

Table 2. Eigenvalues and variation

\begin{tabular}{ccccc}
\hline \hline Item & I & II & III & IV \\
\hline Eigenvalues & 11.10 & 2.91 & 1.89 & 1.44 \\
\hline \% expl.Var. & 27 & 17 & 13 & 13 \\
\hline cum\% expl.Var. & 27 & 44 & 57 & 70 \\
\hline \hline
\end{tabular}

Table 3. Correlations between types

\begin{tabular}{ccccc}
\hline \hline Type & I & II & III & IV \\
\hline I & 1 & - & - & - \\
\hline II & .507 & 1 & - & - \\
\hline III & .623 & .397 & 1 & - \\
\hline \hline
\end{tabular}

Table 4. P-sample distribution by type and factor loading

\begin{tabular}{|c|c|c|c|c|c|c|c|}
\hline Type & ID & sport & $\begin{array}{l}\text { Participation } \\
\text { frequency }\end{array}$ & $\begin{array}{c}\text { Participation } \\
\text { intensity }\end{array}$ & $\begin{array}{l}\text { Participation } \\
\text { duration }\end{array}$ & $\begin{array}{c}\text { Participation } \\
\text { motive }\end{array}$ & $\begin{array}{l}\text { Factor } \\
\text { loading }\end{array}$ \\
\hline \multirow{8}{*}{$\begin{array}{c}\mathrm{I} \\
(\mathrm{N}=8)\end{array}$} & 1 & Skating & 4-5 times a week & Medium-high & $2-3$ hrs. & Leisure-fun & .813 \\
\hline & 3 & GX & 2-3 times a week & Moderate & 1-2 hrs. & Self-realization & .674 \\
\hline & 7 & Volleyball & 1 time a week & Medium-high & 1-2 hrs. & Leisure-fun & .821 \\
\hline & 10 & GX & 4-5 times a week & Moderate & 1-2 hrs. & Self-realization & .662 \\
\hline & 14 & Soccer & 1 time a week & Medium-high & 2-3 hrs. & Stress & .813 \\
\hline & 15 & GX & 4-5 times a week & Moderate & 2-3 hrs. & Leisure-fun & .762 \\
\hline & 17 & Swimming & 2-3 times a week & Moderate & 30-60 min. & Stress & .689 \\
\hline & 23 & GX & 2-3 times a week & Moderate & 1-2 hrs. & Stress & .725 \\
\hline \multirow{6}{*}{$\underset{(\mathrm{N}=6)}{\Pi}$} & 5 & Soccer & 2-3 times a week & Moderate & 1-2 hrs. & Self-realization & .595 \\
\hline & 6 & Badminton & 4-5 times a week & Medium-high & $2-3$ hrs. & Health-fitness & .739 \\
\hline & 8 & Swimming & 2-3 times a week & Medium-high & 1-2 hrs. & Self-realization & .668 \\
\hline & 12 & Tennis & 2-3 times a week & Medium-low & 30-60 min. & Self-realization & .683 \\
\hline & 13 & Basketball & 2-3 times a week & Medium-low & 30-60 min. & Health-fitness & .621 \\
\hline & 24 & Soccer & 2-3 times a week & Moderate & 30-60 min. & Leisure-fun & .652 \\
\hline \multirow{4}{*}{$\underset{(\mathrm{N}=4)}{\mathrm{III}}$} & 2 & GX & 2-3 times a week & Medium-high & 2-3 hrs. & Leisure-fun & .758 \\
\hline & 4 & Climing & 4-5 times a week & Medium-high & 3 hrs or more. & Leisure-fun & .590 \\
\hline & 16 & Volleyball & 2-3 times a week & Medium-high & 1-2 hrs. & Leisure-fun & .651 \\
\hline & 25 & GX & 1 time a week & Medium-low & 30-60 min. & Weight-shape & 666 \\
\hline \multirow{3}{*}{$\begin{array}{c}\mathrm{IV} \\
(\mathrm{N}=3)\end{array}$} & 9 & Basketball & 2-3 times a week & Medium-low & 1-2 hrs. & Self-realization & .630 \\
\hline & 20 & Soccer & 4-5 times a week & Moderate & 1-2 hrs. & Leisure-fun & .877 \\
\hline & 21 & Badminton & 1-2 times a month & Low & 10-30 min. & Weight-shape & .586 \\
\hline \multirow{4}{*}{$\begin{array}{c}\mathrm{n} / \mathrm{a} \\
(\mathrm{N}=4)\end{array}$} & 18 & Soccer & 2-3 times a week & Moderate & 1-2 hrs. & Leisure-fun & - \\
\hline & 19 & Tennis & 2-3 times a week & Medium-high & 1-2 hrs. & Health-fitness & - \\
\hline & 22 & Volleyball & 4-5 times a week & Medium-high & 2-3 hrs. & Health-fitness & - \\
\hline & 11 & Swimming & 2-3 times a week & Moderate & 30-60 min. & Leisure-fun & - \\
\hline
\end{tabular}


Q-요인분석 결과, 25 명의 P-표본 중 21 명이 4 개 유 형을 설명하는 것으로 나타났다. 구체적으로 8명이 유형 I 의 전형으로 나타났으며, 유형 II 6명, 유형III 4명, 유 형IV 3명 순이다. 한편, 3 명은 두 개의 유형에서 높은 요 인적재치가 확인되어 교차적재(cross loading)가 발견 되었으며, 나머지 1 명은 어떤 유형에도 통계적으로 유의미 한 적재치를 나타내지 않았다. 유형별 P-sample의 분포와 요인적재치 그리고 생활체육 참여 형태에 관한 내용은 〈Table 4〉와 같다.

\section{유형 해석}

유형 해석은 앞서 Q-요인분석에 의해 발견된 네 개 유형 을 연구자가 직접 해석 및 명명하는 작업으로 $\mathrm{Q}$ 방법론에서 매우 중요한 작업이다. 다시 말해, 소프트웨어 패키지인 $\mathrm{PQmethod}$ 가 통계적 유의미성을 판단해 유형을 추출하였 다면, 추출된 유형으로부터 그 의미를 발견하고 각 유형에 적합한 주제(theme)를 부여하는 일은 연구자의 역할인 것 이다. 이때 연구자는 각 유형별 대표 Q-표본(표준점수 \pm 1.0 이상인 진술문)을 심층적으로 비교 및 분석함으로써 유형별 특징과 유형 간 유사성을 탐색할 수 있다. 여기서 +1.0 이상의 진술문은 '선호하는 코칭 행동' 으로 강하게 수 용한 반면, -1.0 이상의 진술문은 '선호하지 않은 코칭 행동' 으로 이해할 수 있다. 그 결과, 유형 I 은 '소통-인성 중시 형', 유형 II는 ‘기능-몰입 지향형', 유형 III은 ‘과정-흥미 중 시형', 유형 IV는 ‘기능-포괄 지향형' 으로 각각 명명하였다.

\section{유형 I : 소통-인성 중시형}

유형 I 은 고유치 11.10 으로 연구의 총 설명변량의 $27 \%$ 를 설명하였으며, 8 명의 연구 참여자가 통계적으로 유의미 한 상관성을 보이고 있다. 표준점수(Z-score)가 \pm 1.0 이상 인, 즉 강한 긍정과 부정을 나타내는 Q-표본은 총 9개로 나 타났다. 유형 I 의 응답자들은 '칭찬을 자주 한다 $(\mathrm{Z}=1.537)$ ' 를 가장 긍정적으로 수용하였으며, '기술만큼 인성을 중요 시한다(Z=1.420)', '연습 계획과 목표를 참여자와 함께 설 정한다(Z=1.272)', '표현방식(언어, 말투, 표정, 행동)이 부 드럽다(Z=1.262)' 순이다. 반면에 '실력 위주로 평가한다 ( $\mathrm{Z}=-1.912)^{\prime}$ 를 가장 부정적으로 수용하였으며, '남성과 여 성의 역할을 구분한다(Z=-1.868)', '결과에 따른 보상과 처 벌을 제공한다(Z=-1.151)', '연습의 난이도와 강도가 높다
(Z=-1.026)', '이론(과학)보다는 자신의 경험을 토대로 지 도한다(Z=-1.021)' 순이다. 유형 I 의 주요 Q-표본 및 표준 점수는 〈Table 5〉와 같다.

긍정적 수용의 주요 핵심어는 칭찬, 인성, 의사결정, 표현 이며, 부정적 수용은 기능 중심의 연습 및 평가, 젠더 고정관 념, 일방적 지시 등이다. 이를 종합해볼 때, 유형 I 은 코치와 의 의사소통, 코치의 인성을 중요시하는 유형으로서 '소통인성 중시형'으로 명명할 수 있다. 다음은 유형 I 의 응답자 들이 대표 Q-표본을 선택한 이유이다.

Table 5. Principle Q-sample and Z-score on Type I

\begin{tabular}{clr}
\hline \hline No. & \multicolumn{1}{c}{ Q-sample } & Z-score \\
\hline 12 & My coach often compliments me. & 1.537 \\
\hline 11 & My coach regards personality as much as skill. & 1.420 \\
\hline 5 & My coach sets plans and goals with participants. & 1.272 \\
\hline 13 & My coach is soft in expression. & 1.262 \\
\hline \hline 14 & $\begin{array}{l}\text { My coach teaches based on his own experience } \\
\text { rather than the theory (science) }\end{array}$ & -1.021 \\
\hline 20 & My coach offers high difficulty and strength. & -1.026 \\
\hline 17 & $\begin{array}{l}\text { My coach is clear on compensation and } \\
\text { punishment depending outcome. }\end{array}$ & -1.151 \\
\hline 4 & $\begin{array}{l}\text { My coach distinguishes the roles of male and } \\
\text { female. }\end{array}$ & -1.868 \\
\hline 15 & $\begin{array}{l}\text { My coach only evaluates the participants with } \\
\text { their skills. }\end{array}$ & -1.912 \\
\hline \hline
\end{tabular}

"실력으로 사람을 판단하는 것은 옳지 않음(ID 1)", "칭찬은 무동기 를 동기로 바꿀 수 있기 때문(ID 3)", "스포츠에는 성 구분이 없다고 생각함(ID 7)", "표현방식은 참여자의 동기에 크게 영향을 미침(ID 10)", "팀스포츠일수록 칭찬은 운동 분위기나 사기에 있어 필수적 임(ID 14)", "배우러 온 사람에게 실력 평가는 의미가 없음(ID 15)", "실력보다 매너가중요함(ID 17)", "코치가주도적으로 이끌 기보다 함께 하는 코칭 방법을 더 선호(ID 23)"

\section{유형 II : 기능-몰입 지향형}

유형 II는 고유치 2.91 로 총 변량의 $17 \%$ 를 설명하였으 며, 6명의 응답자가 통계적으로 유의미한 상관성을 보이고 있다. 표준점수가 \pm 1.0 이상인 Q-smaple은 총 6개로 나 타났다. 유형 II의 응답자들은 '코칭 시 열정이 넘친다 (Z=1.694)'를 가장 긍정적으로 수용하였으며, '기술 향상을 가장 중요시한다(Z=1.464)', '동작을 직접 시범으로 보여준 다(Z=1.220)' 순이다. 반면에 '연습과 관련된 인문적 활동 
(글쓰기, 발표, 그룹토론)을 지도한다(Z=-2.099)'를 가장 부정적으로 수용하였으며, '연습과 관련된 인문적 자료(책, 영화, 그림 등)를 활용한다(Z=-1.494)', '잦은 피드백보다 는 말을 아낀다(Z=-1.364)' 순이다. 유형 II의 주요 Q-표본 및 표준점수는 〈Table 6)과 같다.

Table 6. Principle Q-sample and Z-score on Type II

\begin{tabular}{clr}
\hline \hline No. & \multicolumn{1}{c}{ Q-sample } & Z-score \\
\hline 3 & My coach is full of passion when coaching. & 1.694 \\
\hline 23 & $\begin{array}{l}\text { My coach regards improving skills as the most } \\
\text { important. }\end{array}$ & 1.464 \\
\hline 24 & My coach demonstrates the motion directly. & 1.220 \\
\hline \hline 19 & My coach avoids frequent feedback. & -1.364 \\
\hline 10 & $\begin{array}{l}\text { My coach utilizes humanistic resources related } \\
\text { to the practice. }\end{array}$ & -1.494 \\
\hline 9 & $\begin{array}{l}\text { My coach directs the humanistic activities } \\
\text { related to the practice. }\end{array}$ & -2.099 \\
\hline \hline
\end{tabular}

긍정적 수용의 핵심어는 열정, 기능 향상, 동작 시범이며, 부정적 수용은 인문적 활동, 무반응 등이다. 이를종합해볼 때, 유형 II는 참여자의 기능 향상과 코치의 열정적 지도를 지향하는 유형으로서 '기능-몰입 지향형'으로 분류할 수 있 다. 다음은 유형 II의 응답자들이 대표 Q-표본을 선택한 이 유이다.

"시범이 기술 향상에 많이 도움되었음(ID 5)", "개인 기술과 장점이 최대한 발휘되어야 흥미유발과 참여를 지속할 수 있음(ID 6)", "장 단점 피드백이 없으면 소외, 무시 받는 느낌이고 무엇이 잘못됐는지 모름(ID 8)", "기술이 최대한 항상되면 코칭이 잘 되었다고 판단함 (ID 12)", "나에게 잠재력 발견은 최우선임(ID 13)", "코치가 열정 이 넘치면 참여 능동성이 생김(ID 24)"

\section{유형III: 과정-흥미 중시형}

유형피은 고유치 1.89 로 총 변량의 $13 \%$ 를 설명하였으 며, 4 명의 응답자가 통계적으로 유의미한 상관성을 보이고 있다. 표준점수가 \pm 1.0 이상인 Q-smaple은 총 6 개로 나 타났다. 유형피의 응답자들은 '결과보다 과정을 중요시한다 ( $\mathrm{Z}=1.976)$ '를 가장 긍정적으로 수용하였으며, '흥미 유발을 위해 노력한다 $(Z=1.618)$ ', '기술만큼 인성을 중요시한다 ( $\mathrm{Z}=1.296)$ ' 순이다. 반면에 '실력 위주로 평가한다 ( $\mathrm{Z}=-1.772)^{\prime}$ 를 가장 부정적으로 수용하였으며, '연습과
관련된 인문적 활동(글쓰기, 발표, 그룹토론)을 지도한다 ( $\mathrm{Z}=-1.674)$ ', '연습과 관련된 인문적 자료(책, 영화, 그림 등)를 활용한다(Z=-1.491)' 순이다. 유형피의 주요 Q-표본 및 표준점수는 〈Table 7〉과 같다.

Table 7. Principle Q-sample and Z-score on Type III

\begin{tabular}{clr}
\hline \hline No. & \multicolumn{1}{c}{ Q-sample } & Z-score \\
\hline 7 & $\begin{array}{l}\text { My coach values the process more than the } \\
\text { result. }\end{array}$ & 1.976 \\
\hline 8 & My coach makes an effort for interest. & 1.618 \\
\hline 11 & My coach regards personality as much as skill. & 1.296 \\
\hline \hline 10 & $\begin{array}{l}\text { My coach utilizes humanistic resources related } \\
\text { to the practice. }\end{array}$ & -1.491 \\
\hline 9 & $\begin{array}{l}\text { My coach directs the humanistic activities } \\
\text { related to the practice. }\end{array}$ & -1.674 \\
\hline 15 & $\begin{array}{l}\text { My coach only evaluates the participants with } \\
\text { their skills. }\end{array}$ & -1.772 \\
\hline \hline
\end{tabular}

긍정적 수용의 핵심어는 과정, 흥미, 인성이며, 부정적 수 용은 기능 중심의 연습 및 평가, 인문적 활동 등이다. 유형III 은 과정 중심과 흥미 유발을 지향하는 유형으로서 '과정-흥 미 중시형'으로 명명할 수 있다. 다음은 유형피의 응답자들 이 대표 Q-표본을 선택한 이유이다.

"흥미가 있어야 그것이 여가든 직업이든 지속할 수 있다고 생각함 (ID 2)", "최선을 다해도 결과는 안 좋을 수 있음(ID 4)", "과정이 즐거우면 결과가 기대한 기준보다 낮더라도 만족스럽다고 생각함 (ID 16)", "첫 번째로 재미가 있어야 운동시간이 기다려지기 때문 (ID 25)"

\section{유형IV: 기능-포괄 지향형}

유형IV는 고유치 1.44 로 총 변량의 $13 \%$ 를 설명하였으며, 3명의 응답자가 통계적으로 유의미한 상관성을 보이고 있다. 표준점수가 \pm 1.0 이상인 Q-smaple은 총 9개로 나타났다. 유형IV의 응답자들은 '기술 향상을 가장 중요시한다 (Z=1.647)'를 가장 긍정적으로 수용하였으며, '개인 수준별 로 맞춤형 프로그램을 제공한다( $\mathrm{Z}=1.483)$ ', '나의 장단점을 지적해준다(Z=1.396)', '동작을 직접 시범으로 보여준다 (Z=1.303)', '동료들과의 교류 기회를 자주 제공한다 (Z=1.123)', ‘팀 중재 능력(통솔력)이 뛰어나다( $\mathrm{Z}=1.093)$ ' 순이다. 반면에 '남성과 여성의 역할을 구분한다(Z=-1.957)' 
를 가장 부정적으로 수용하였으며, '팀 전체보다는 개인의 발 전을 중요시한다(Z=-1.576)', '운동 외에도 고민 상담을 해 준다(Z=-1.445)' 순이다. 유형 $\mathrm{V}$ 의 주요 Q-표본 및 표준점 수는 〈Table 8)과 같다.

Table 8. Principle Q-sample and Z-score on Type IV

\begin{tabular}{clc}
\hline \hline No. & \multicolumn{1}{c}{ Q-sample } & Z-score \\
\hline 23 & $\begin{array}{l}\text { My coach regards improving skills as the most } \\
\text { important. }\end{array}$ & 1.647 \\
\hline 1 & $\begin{array}{l}\text { My coach offers a differentiated program for } \\
\text { each individual level. }\end{array}$ & 1.483 \\
\hline 25 & $\begin{array}{l}\text { My coach points out my strengths and } \\
\text { weaknesses. }\end{array}$ & 1.396 \\
\hline 24 & My coach demonstrates the motion directly. & 1.303 \\
\hline 18 & $\begin{array}{l}\text { My coach often provides opportunities for } \\
\text { interaction with teammates. }\end{array}$ & 1.123 \\
\hline 2 & My coach is excellent in team mediation ability. & 1.093 \\
\hline \hline 21 & My coach counsels personal anxieties. & -1.445 \\
\hline 16 & $\begin{array}{l}\text { My coach emphasizes personal development } \\
\text { rather than team. }\end{array}$ & -1.576 \\
\hline 4 & $\begin{array}{l}\text { My coach distinguishes the roles of male and } \\
\text { female. }\end{array}$ & -1.957 \\
\hline \hline
\end{tabular}

긍정적 수용의 핵심어는 기능 향상, 수준별 맞춤 지도, 장 단점 파악, 동작 시범, 참여자 간 교류, 팀 중재력(통솔력)이 며, 부정적 수용은 젠더 고정관념, 개인 중심, 지나친 관심 등이다. 이를 종합해볼 때, 유형 $\mathrm{V}$ 는 기능 향상과 공동체를 지향하는 유형으로서 '기능-포괄 지향형'으로 명명할 수 있 다. 다음은 유형 $\mathrm{V}$ 의 응답자들이 대표 Q-표본을 선택한 이 유이다.

"통솔력이 뛰어난 지도자는 신뢰가 많이 감(ID 9)", "사람마다다른 특성을 무시하는 것은 옳지 않음(ID 20)", "개인별 차이를 고려한 다는 것은 그 만큼 관심이 많은 거라고 생각함(ID 21)"

\section{논의}

앞서 유형 분석 및 해석을 통해 총 네 개 유형과 각 특성을 확인하였다. 이들 유형은 소통-인성 중시형( I), 기능-몰입 지향형(II), 과정-흥미 중시형(III), 기능-포괄 지향형(IV)으 로 유형화되었으며, 유형 간 유의미한 차이뿐만 아니라 경
우에 따라 유사성도 보이고 있다. 본 연구는 논의 과정에서 네 개 유형에 관한 재범주화 작업을 실시하였으며 그 결과, 소통-인성 중시형( I)과 과정-흥미 중시형(III)을 “비기능적 가치 지향형' 으로, 기능-몰입 지향형(II)과 기능-포괄 지향 형(IV)을 '기능적 가치 지향형' 으로 범주화하였다. 이에 본 절에서는 '비기능적 가치 지향형'에 해당하는 유형 I 과 유 형II를, '기능적 가치 지향형'에 포함되는 유형 II와 유형IV 를 비교 분석함으로써 학술적 및 실용적 논의를 제공하고자 한다.

\section{비기능적 가치 지향형: 소통-인성( I ), 과정-흥미(III)}

유형 I 과 유형피이 스포츠 참여로부터 기대하는 가치와 그에 따른 코칭 행동은 명확하게 관찰된다. 이들 유형은 스 포츠 참여 시 코치의 인성이나 태도에 높은 가치를 두었으 며, 수행 결과보다는 참여 과정과 재미에 초점을 두고 있다. 또한, 긍정적 피드백(칭찬), 부드러운 표현방식(언어, 말투, 표정, 행동), 의사결정 참여 등 코치와의 상호작용에 민감하 게 반응한다. 반면에 이들 유형은 기술 및 결과 중심의 평가 방식에 대해 공통적으로 강한 부정적 수용인식을 보이고 있 다. 코치의 경험적 코칭 행동과 지나친 연습량 및 난이도 역 시 강한 부정적 반응을 나타냈다.

이러한 관점에서 유형 I 과 유형Iㅇ은 스포츠 참여 시 기능 (기술) 향상보다는 비기능적 가치를 기대하고 있으며, 이는 코칭 경험에 대한 주관적 수용인식에서 뚜렷하게 나타났다. 여기서 비기능적 가치란 스포츠가 지닌 규범적, 심미적, 유 희적 요소로서 특정 종목의 기술(skill)과는 상반된 개념이 다(Jeon, Noh \& Choi, 2008; Kim et al., 2003; Lee, 2005; Oh, 2000; Park, 2015). 스포츠의 가치를 '사회문 화적 소통 도구'도 바라본 Goo(2011)의 연구도 비슷한 맥 락에서 이해할 수 있다.

Cho, Oh \& Chung(2018)은 스포츠 소비자로서 중년 여성들의 수영 참여와 기대하는 가치 및 욕구를 탐색한 결 과, 참여자들은 강사와 회원, 회원과 회원 사이의 상호작용 을 매우 중요한 가치로 평가하였다. 그 배경으로 육아와 가 사노동으로 잃어버린 사회적 교류를 언급하였다(Cho, Oh \& Chung, 2018). 이들 연구는 여성 참여자가 스포츠 참여 (특히, 지도자)로부터 비기능적 가치를 기대하는 전형적인 사례로 볼 수 있다. 평생교육의 관점에서 여성의 신체활동 경험을 분석한 Park, $\operatorname{Kim} \& \operatorname{Kim}(2015)$ 의 연구 역시 참여 
자들이 스포츠 참여로부터 비기능적 가치를 기대하고 있음 을 잘 보여준다. 구체적으로 남성 및 기능 중심적 코칭은 무 기력과 소외(소극적 구경꾼, 들러리)를 야기하고, 여성의 신 체 및 정신적 특성이 고려되지 않은 지도 방식은 수치심과 창피함으로 기억된다(Park, Kim \& Kim, 2015). 이는 지 도자의 소통, 인성, 과정, 흥미의 인식 부재로부터 발생했다 고 볼 수 있다. 무엇보다 이러한 경험은 지도자는 물론 신체 활동에 대한 부정적 인식으로 이어졌다.

기능(기술)이 경기수행능력과 경기결과에 직접적인 영향 을 미친다면, 비기능적 가치는 스포츠 참여로부터 기대할 수 있는 2 차 경험이다. 그리고 이러한 2 차 경험은 가르치는 내용으로서 스포츠를 전달하는 사람, 즉 코치의 역할에 따 라 상당한 영향을 받는다. 같은 맥락에서 $\operatorname{Kim}(2018)$ 은 스 포츠지도사는 스포츠의 가치를 체계적으로 이해해야 한다 고 주장하면서 승리지상주의, 승패업적주의와 같은 이데올 로기에 대한 저항력을 가져야 한다고 하였다. 다시 말해, 코 치가 기능 향상 및 결과에 초점화된 코칭 행동을 추구한다 면, 참여자들은 앞서 언급한 스포츠의 다양한 가치들을 덜 경험하거나 전혀 경험하지 못할 수도 있다는 것이다. 그리 고 이러한 사실은 유형 I 및 유형페과 같은 여성 참여자들에 게 기능 향상보다는 스포츠가 지닌 다양한 가치들이 발현될 수 있는 코칭을 고려해야 함을 의미한다.

여기서 유의해야 할 점은 모든 여성 참여자들이 스포츠의 기능(기술)적 가치보다 소통, 인성, 과정, 흥미와 같은 비기 능적 가치를 추구하는 것이 아니라는 점이다. 다음 항에서 살펴볼 기능적 가치 지향형(유형 I, III)은 본 항에서 살펴본 비기능적 가치 지향형과 상반된 반응을 보였기 때문이다. 이와 관련해서는 다음 항에서 자세히 살펴보고자 한다.

추가로 주목할 점은 유형 I 과 유형Iㅣㅇㅣ 큰 틀에서 스포츠 참여로부터 비기능적 가치를 기대하고 있음에도 불구하고 특정 Q-표본에서 유의미한 차이점을 보였다는 점이다. 표 준점수의 차이가 \pm 1.0 인 Q-표본을 살펴보면, '연습과 관 련된 인문적 자료(책, 영화, 그림 등)를 활용한다 (dif.=1.233)', '연습과 관련된 인문적 활동(글쓰기, 발표, 그룹토론)을 지도한다(dif.=1.066)', '남성과 여성의 역할을 구분한다(dif.=-1.052)'가 두드러진 차이를 나타냈다. 유형 I 과 유형III 간의 주요 표준점수 차이는 〈Table 9〉와 같다.
Table 9. Differences between types I and III

\begin{tabular}{clccc}
\hline \hline No. & \multicolumn{1}{c}{ Q-sample } & I & III & Dif. \\
\hline 10 & $\begin{array}{l}\text { My coach utilizes humanistic } \\
\text { resources related to the practice. }\end{array}$ & -0.258 & -1.491 & 1.233 \\
\hline 9 & $\begin{array}{l}\text { My coach directs the humanistic } \\
\text { activities related to the practice. }\end{array}$ & -0.608 & -1.674 & 1.066 \\
\hline 4 & $\begin{array}{l}\text { My coach distinguishes the } \\
\text { roles of male and female. }\end{array}$ & -1.868 & -0.816 & -1.052 \\
\hline \hline
\end{tabular}

인성과 태도를 중요시하는 유형 I 과 달리, 유희적 요소를 기대하는 유형피은 인문적 코칭에 대해 강한 부정적 수용인 식을 보이고 있다. 이는 스포츠 참여로부터 흥미나 재미를 기대하는 유형은 인문적 자료나 활동을 통해 스포츠를 간접 적으로 체험하기보다는 직접 체험을 더욱 선호하는 것으로 이해할 수 있다. 또한, 유형 I 과 유형III 모두 여성 참여자임 에도 '코치의 성 역할 구분'에 대해서는 그 수용 정도에 큰 차이를 보였다. 규범적 요소를 중요시하는 유형 I 은 강한 부정적 수용을 나타낸 반면, 유희적 요소에 가치를 두는 유 형피은 상대적으로 덜 민감하게 반응하였다. 이러한 차이점 들은 여성 생활체육 참여자를 지도하는 코치의 역할과 행동 에 실용적 의의를 제공한다고 할 수 있다. 더 나아가 참여자 의 주관적 수용인식을 유형화하고 각 유형 간 유사성 및 차 이점을 규명하는데 있어 Q방법론의 학술적 유용성을 재확 인하였다.

\section{기능적 가치 지향형: 기능-몰입(II), 기능-포괄(IV)}

유형 II와 유형 $\mathrm{V}$ 는 앞서 논의한 두 유형( I , III)과는 뚜렷 하게 대비된다. 이들 유형은 스포츠를 직접 수행하는데 필 요한 기능적 요소에 높은 가치를 두고 있으며, 기술 향상과 경기수행능력에 초점화된 코칭을 기대하고 있다. 구체적으 로 스포츠 참여 시 코치의 강한 열정과 직접적인 동작 시범, 참여자의 장단점 지적 등에 대해 강한 긍정적 수용을 나타냈 다. 같은 맥락에서 잦은 피드백보다는 말을 아끼는 소극적 코칭 행동에 대해서는 강한 부정적 반응을 보였다.

이를 종합해보면, 유형 II와 유형 $\mathrm{N}$ 는 스포츠 참여 시 기 능(기술)을 향상시키는데 필요한 코칭 행동을 기대한다. 이 는 스포츠의 비기능적 요소에 보다 높은 가치를 두었던 유형 I 과 유형피과는 상반된 유형으로서 '기능적 가치 지향형' 이라고 할 수 있다. Kilpatrick, Hebert \& Bartholomew(2005)는 여자 대학생들의 스포츠(sport)와 
운동(exercise)의 참여 동기를 구분하여 살펴보았는데 그 결과, 스포츠 참여는 '도전'과 같은 스포츠의 본질적 (intrinsic) 속성이 발견된 반면, 운동 참여는 외모, 체중, 스 트레스 관리와 같은 외적 동기(extrinsic motives)로 나타 났다. 이러한 관점에서 유형 $\Pi$ 와 유형 $\mathrm{V}$ 의 개인적 특성을 살 펴보면(〈Table 4〉참고), 축구, 농구, 배드민턴 등이 규칙적 인 참여 종목으로 나타나 경쟁 스포츠의 성격이 짙음을 알 수 있다. 이는 레저스포츠보다는 경쟁적 속성이 강한 스포 츠 종목의 코치(특히, 여성 참여자를 대상으로 하는 코치)에 게 중요한 시사점을 제공한다.

그동안 일부 연구는 '구조화된(기술 및 남성 중심적으로 표준화된) 스포츠'를 여성의 스포츠 참여 장벽요인으로 보 고하였다(Lee et al., 1999; Wigfield et al., 1997). 그러 나 이는 본 연구에서 발견한 유형 II와 유형 $\mathrm{N}$ 의 '기능적 가 치 지향형'에는 일부 유효하지 않음을 보여준다. 스포츠 코 칭을 계획 및 전달하는 과정에서 스포츠의 속성인 '기능(기 술)', '도전', '경쟁'을 간과하는 오류를 유의해야 한다는 것 이다. 특히, 유형 II와 유형 IV에 해당하는 여성 참여자에게 는 기능적 요소를 충족할 수 있는 코칭 행동이 더욱 요구된 다.

여성 스포츠 참여자의 '기능적 가치 지향'을 지지해주는 사례로, Hong \& Yim(2018)와 Hong, Kim \& Yim(2016) 의 연구가 있다. Hong \& Yim(2018)은 '성과 상반된 젠더 유형 스포츠, 즉 남성적 종목에 참여하는 여성 참여자들이 특정 종목의 기술, 체력, 단결, 강렬함이라는 본질적 측면에 매력을 느끼고 있다고 하였다. 한편, Hong, Kim \& Yim(2016)은 연구 참여자들이 신체접촉이 많거나 공(ball) 을 사용하는 구기 종목을 남성스포츠로 규정하면서도 해당 종목으로의 참여를 통해 주체성 회복과 성 역할의 인식 변화 를 경험했다고 하였다. 이들 연구는 스포츠 종목을 특정 젠 더유형으로 규정하는 것에 대해 비판적 관점을 제시해주고 있으며 특히, 코칭 행동의 측면에서 중요한 의미를 지니고 있다. 스포츠 참여자의 기능적 또는 비기능적 가치 지향은 남녀의 문제가 아닌 참여 종목의 특성과 참여 동기의 측면에 서 접근해야 한다는 것이다. 이러한 판단은 앞서 살펴본 선 행연구뿐만 아니라 본 연구에서 발견한 유형 II, IV를 통해서 도 재확인할 수 있었다.

유형 III와 유형IV 역시 스포츠의 기능적 속성을 공통적으 로 지향하고 있는 반면, 일부 Q-표본에서 유의미한 차이점을 보였다. 구체적으로 '코칭 시 열정이 넘친다(dif.=2.256)',
'동료들과의 교류 기회를 자주 제공한다(dif.=-1.468)', '연 습과 관련된 인문적 자료(책, 영화, 그림 등)를 활용한다 (dif.=-1.487)'에서 큰 차이를 보였다. 유형 II와 유형IV 간 의 주요 표준점수 차이는 〈Table 10〉과 같다.

Table 10. Differences between types $I I$ and IV

\begin{tabular}{clccc}
\hline \hline No. & \multicolumn{1}{c}{ Q-sample } & II & IV & Dif. \\
\hline 3 & $\begin{array}{l}\text { My coach is full of passion } \\
\text { when coaching. }\end{array}$ & 1.694 & -0.562 & 2.256 \\
\hline 18 & $\begin{array}{l}\text { My coach often provides } \\
\text { opportunities for interaction } \\
\text { with teammates. }\end{array}$ & -0.345 & 1.123 & -1.468 \\
\hline 10 & $\begin{array}{l}\text { My coach utilizes humanistic } \\
\text { resources related to the practice. }\end{array}$ & -1.494 & -0.007 & -1.487 \\
\hline \hline
\end{tabular}

유형 II와 유형 $\mathrm{V}$ 는 코치의 강한 열정에서 눈에 띄는 차이 를 보이고 있다. 이러한 차이는 이들 유형이 기능 향상이라 는 공동 가치를 공유하면서도 그 정도와 방향은 일부 상이함 을 보여준다. 앞서 확인했듯이 유형 프은 시범과 설명, 잦은 피드백 등 상대적으로 모방 중심적이고 통제적인 코칭 행동 을 기대했으며, 이는 유형 ㅍㅇㅇㅘ 같은 참여자들에게는 상대적 으로 강한 통제와 모방 중심적 코칭 행동이 요구된다는 점을 간과해서는 안 된다.

유형IV는 기능 향상을 추구하면서도 한편으로는 수준별 맞춤 프로그램과 참여자들과의 교류 기회 및 팀 중재 능력 (통솔력)을 코치로부터 기대하였다. 이는 부정적 수용 인식 에서도 비슷한 양상을 보였는데, 팀(공동체)보다 개인의 발 전을 중요하게 여기는 코칭 행동에는 강하게 부정하였다. 이처럼 유형 $\mathrm{V}$ 는 기능 향상을 중요시하면서 궁극적으로 모 든 참여자가 함께 성장하는 것을 추구한다. 따라서 코치는 기능 향상을 위한 교수 과정에서 소외되는 참여자가 발생하 지 않도록 주의를 기울이고 수준별 및 개인 특성별로 차별화 된 과제를 제공해야 할 것이다. 또한, Mosston \& Ashworth(2002)은 포괄형 스타일에서 간과하지 말아야 할 점으로 연속적 활동이 가능한 다양한 수준의 과제를 제시 할 것을 권고하였다. 이는 유형IV에도 중요한 학술적 의의 를 지니고 있는데, 그 이유는 유형IV 역시 근본적으로 기능 향상을 추구하기 때문에 '과제의 연속(점진)성'은 코칭 설계 에서 필수적인 요건이기 때문이다. 


\section{결론 및 제언}

본 연구는 특정 변인 간 관계에 초점을 두었던 선행연구 들과 달리, 코칭 수용자(여성 생활체육 참여자)의 내부 관점 (감정, 견해, 가치, 의미, 동기 등)에 주목하였다. 이를 위해 $\mathrm{Q}$ 방법론을 분석 틀로 차용하여 여성 생활체육 참여자의 코 칭 경험에 대한 심리적 주관성, 즉 수용인식과 선호유형을 규명하였다.

그 결과 첫째, 참여자들이 선호한 코칭 행동은 소통-인성 중시형(유형 I), 기능-몰입 지향형(유형 II), 과정-흥미 중시 형(유형III), 기능-포괄 지향형(유형IV)으로 유형화되었다. 둘째, 각 유형의 특징을 살펴본 결과, 유형 I 은 코치와의 의 사소통 및 코치의 인성을 중요시한 반면 기능 중심의 연습 및 평가, 젠더 고정관념, 일방적 지시는 강하게 부정하였다. 유형 II는 참여자의 기능(기술) 향상과 코치의 열정적 지도 를 선호한 반면 인문적 활동과 소극적 반응에는 강한 부정을 나타냈다. 유형피은 과정 중심과 흥미 유발을 선호한 반면 기능 중심의 연습 및 평가와 인문적 활동에는 강한 부정을 보였다. 유형 $\mathrm{N}$ 는 기능 향상과 공동체 발전을 지향하지만 개인 중심 및 젠더 고정관념은 강하게 부정하였다. 마지막 으로 네 개 유형을 ‘비기능적 가치 지향형( I, III)'과 '기능적 가치 지향형(II, IV)' 으로 범주화하여 학술적 및 실용적 의의 를 도출하였다.

결과를 바탕으로 전개한 기능적 및 비기능적 가치 지향형 에 대한 논의는 본 연구가 여성의 관점에서 코칭론에 접근했 으나 결론적으로 스포츠 코칭에 대한 논의는 남녀의 문제보 다는 참여 종목의 특성과 참여 동기의 측면에서 접근해야 함 을 보여준다. 남녀를 구분하여 보다 남성적이고, 보다 여성 적인 스포츠를 제공한다거나 그러한 코칭법을 적용한다는 것은 본 연구에서 만큼은 의미 없다는 것을 확인하였다. 다 시 말해, 스포츠지도자는 남성적 및 여성적 스포츠를 스스 로 규정하는 '젠더 고정관념(Kim \& Park, 2009)'을 경계 하고, 코칭 상황(종목, 참여동기)에 따라 스포츠가 지닌 다 양한 가치를 실현하는데 초점을 두어야 한다는 점이다. 이 런 맥락에서 본 연구에서 확인한 스포츠의 기능적 가치 지향 형(유형 I, III)과 비기능적 가치 지향형(유형 III, IV)은 코칭 내용으로서 유의미한 시사점을 제공해주고 있다.

본 연구는 여성 생활체육 참여자들의 코칭 경험에 관한 수용인식은 물론 그들이 스포츠를 바라보는 관점, 스포츠 참여로부터 기대하는 가치와 규범을 탐색하는 데에도 노력
을 기울였다. 그리고 본 연구를 통해 도출된 각 유형은 여성 스포츠에 관한 사회·심리학적, 철학적 논의에 다양한 관점 을 제공했다는 점에서 학술적 의의가 있다. 또한, 각 유형과 그 특성은 실제 스포츠 현장의 교수법(코칭론)에 기초 자료 를 제공할 수 있다. 특히, 여성 참여자를 P-표본으로 선정한 본 연구의 특성상, 여성을 대상으로 하는 코칭 상황에서 보 다 유의미한 시사점을 제공할 수 있다.

이러한 학술적 및 실용적 기여에도 불구하고 본 연구는 몇 가지 한계점을 지니고 있다. 첫째, $\mathrm{P}-$ 표본 선정에 있어 생활체육 참여종목에 제한을 두지 않았는데 이는 특정 스포 츠 종목이 지닌 특수성을 결과 및 논의에 반영하는데 한계를 보였다. 따라서 후속연구에서는 특정 스포츠 종목을 선정하 여 심층적인 연구를 수행하거나 레저스포츠와 경쟁스포츠, 개인종목과 단체종목과 같이 유사 스포츠를 분류하여 비교 연구를 진행한다면 보다 의미 있는 논의를 제공할 수 있을 것이다. 둘째, $\mathrm{Q}$ 방법론의 특성상 가설 추론에는 유용하지만 본 연구에서 도출한 각 유형을 실증적으로 분석하는 데에는 한계가 있었다. 이에 후속연구에서는 각 유형의 이론적 고 찰과 전문가 검토를 통해 타당도 검증 및 실증분석으로 발전 시켜나갈 필요가 있다.

\section{참고문헌}

Arnold, P. (1997). Sport, ethics and education. London: Cassell. Avolio, B. J., \& Bass, B. M. (2004). Multifactor leadership questionnaire (MLQ). CA: Mind Garden.

Bartholomew, K. J., Ntoumanis, N., \& Thøgersen-Ntoumani, C. (2010). The controlling interpersonal style in a coaching context: Development and initial validation of a psychometric scale. Journal of Sport and Exercise Psychology, 32(2), 193-216.

Bass, B. M. (1985). Leadership and performance beyond expectations. NY: Free Press.

Chelladurai, P., \& Saleh, S. D. (1980). Dimensions of leader behavior in sports: Development of a leadership scale. Journal of Sport Psychology, 2(1), 34-45.

Cheon, S. H. (2011). The influence of multi-dimensional controlling coaching styles on motivation for athletes with disabilities. Journal of Adapted Physical Activity and 
Exercise, 19(4), 162-179.

Cho, H. M., \& Lim, S. Y. (2012). Transference of gender ideologies, its re-production, and teachers' dilemma in physical education in the elementary schools. The Korean Journal of Elementary Physical Education, 18(2), 1-14.

Cho, K. M., Oh, J. H., Chung, Y. M. (2018). A study on the structure and meaning of swimming participation by middle eastern women in their 50s. The Korean Journal of Physical Education, 57(3), 281-291.

Cho, O. S. (2015). An educational contemplation on pedagogical significance of elite sports: A little view of sports teaching and sports coaching. Korean Association of Sport Pedagogy, 22(1), 151-171.

Cho, O. S. (2017). Exploring academic meaning of pedagogical approach to sport coaching research. Korean Association of Sport Pedagogy, 24(1), 43-60.

Choi, E. C. (2012). Whole athlete development and humanities-oriented sports coaching: Reconceptualizing sports coaching as a pedagogical endeavor. Korean Association of Sport Pedagogy, 19(2), 1-25.

Choi, Y. J., Choi, K. Y., \& Kim, K. J. (2011). Development and validation of taekwondo instructor`s coaching style. Korean Journal of Physical Education, 50(6), 285-297.

Coakley, J., \& White, A. (1992). Making decisions: Gender and sport participation among British adolescents. Sociology of Sport Journal, 9(1), 20-35.

Cockburn, C., \& Clarke, G. (2002). Everybody's looking at you!: Girls negotiating the 'femininity deficit' they incur in physical education. Women's Studies International Forum, 25(6), 651-665.

Garrett, R. (2004). Negotiating a physical identity: Girls, bodies and physical education. Sport, Education and Society, 9(2), 223-237.

Gomez-Baya, D., Mendoza, R., \& Tomico, A. (2018). The prospective relationship of sport and physical activity with life satisfaction after a one-year follow-up: An examination of gender differences during mid-adolescence. Cuadernos de Psicología del Deporte, 18(2), 69-186.

Goo, K. B. (2011). Possibility and Value of Sports as Culture Contents. Korean Journal of Physical Education, 50(5), 57-66.

Hong, J. E., Kim, M. Y., \& Yim, Y. S. (2016). A qualitative research of female college student's participation challenges in 'men`s sports'. Korean Journal of Leisure, Recreation \& Park, 40(1), 15-31.

Hong, J. E., \& Yim, Y. S. (2018). Implementation of gender stereotype in sports: focusing on the experience of participating in opposite gender typing sports. The Korean Journal of Cultural Sociology, 26(2), 161-215.

Institute of Youth Sport. (2000). Towards girl-friendly physical education: The Nike/YST girls in sport partnership project final report. Loughborough: Institute of Youth Sport.

Jeon, J. W., Noh, T. W., \& Choi, J. W. (2008). A Study on Sports Value Systems of Participants in Sports for All activities Based on Social Strata. Journal of Sport and Leisure Studies, 32(1), 93-105.

Jeong, K. S., Ahn, Y. O., \& Shin, K. C. (2008). Exploring the realities and causes of the sexism styles expressed in elementary school teachers` Language during the physical education classes. Korean Association of Sport Pedagogy, 15(3), 105-121.

Kilpatrick, M., Hebert, E., \& Bartholomew, J. (2005). College students' motivation for physical activity: differentiating men's and women's motives for sport participation and exercise. Journal of American College Health, 54(2), 87-94.

Kim, D. J. (2010). Causes of alienation in physical education from the perspectives of middle school students. Korean Association of Sport Pedagogy, 17(3), 1-21.

Kim, H. K. (1992). Understanding and applying of Q methodol ogy. Seoul: Sogang University Journalism \& Culture Institute.

Kim, H. K. (2008). Q methodology: Philosophy of science, the oy, analysis and application. Seoul: Communicationbooks.

Kim, H. S. (2018). Sport coach and sport philosophy. Philosophy of Movement: Journal of the Korean Society for the Philosophy of Sport, Dance \& Martial Arts, 26(4), 21-30.

Kim, I. W., Shin, M. J., \& Kwon, S. H. (2014). The impact of perceived coaches' interpersonal behaviors on the relationship between self-esteem and subjective happiness in young soccer players. Journal of Coaching Development, 16(1), 149-156.

Kim, J. H., \& Park, S. J. (2009). Sexual discrimination in sport. The Korean Journal of Physical Education, 48(5), 25-33. 
Kim, K. N., Shin, H. K., Kim, M. S., \& Lee, S. Y. (2003). The Concept and Characterization of Dancesport and Its Popularization Measures. Philosophy of Movement: The Journal of Korean Philosophic Society for Sport and Dance, 11(2), 355-372.

Kim, N. K. (2009). A research on application of coed physical education class in new sports: Focusing on students` responses. Korean Association of Sport Pedagogy, 16(3), 17-34.

Kim, N. K., \& Kim, Y. B. (2014). Study of differing viewpoints of new sports between male and female students. Journal of Research in Curriculum Instruction, 18(2), 343-363.

Kim, S. Y., \& Park, S. H. (2016). Verification of a causal model among the process of self-regulation motivation and sports performance under the coach's behavior. Korean Journal of Sport Science, 27(1), 169-180.

Kim, Y. H. (2009). Developing teaching strategies for alienated students in physical education classes. Korean Association of Sport Pedagogy, 16(1), 41-56.

Kim, Y. K. (2012). Analysis of casual structure among sports coach's coaching knowledge, leadership and sports behavior. Korean Journal of Sport Studies, 51(1), 143-152.

Korean Society for the Science Study of Subjectivity. (2002). Subjectivity study. Seoul: Communicationbooks.

Korean Society for the Science Study of Subjectivity. (2014). Application and Case of Q methodology. Seoul: Prunsasang.

Lacy, A. C., \& Darst, P. W. (1985). Systematic observation of behaviors of winning high school head football coaches. Journal of Teaching in Physical Education, 4(4), 256-270.

Lee, A. M., Fredenburg, K., Belcher, D., \& Cleveland, N. (1999). Gender differences in children's conceptions of competence and motivation in physical education. Sport, Education and Society, 4(2), 161-174.

Lee, G. I., \& Yu, T. H. (2010). Exploration on educational limits and practical alternative of 'new sports' teaching to review with logics of P.E. as a subject. Korean Association of Sport Pedagogy, 17(4), 83-100.

Lee, J. Y. (2005). The Anthropological Value of Dance Sport and the Practice of Encounter through the Play. Philosophy of Movement: The Journal of Korean Philosophic Society for Sport and Dance, 13(2), 177-190.
Lee, W. M. (2018). The effects of coaching language on sport confidence and perceived performance of high school soccer players. Journal of Coaching Development, 20(2), 32-39.

Lee, Y. K. (2016). Exploring tennis coaching styles through self-study. Korean Association of Sport Pedagogy, 23(1), 87-108.

McIntyre, A. (1984). After virtue: A study in moral theory. London: Duckworth

McKeown, B., \& Thomas, D. B. (2013). Q methodology (Vol. 66). CA: Sage Publications.

Ministry of Culture, Sports and Tourism. (2012). 2012 National Survey on Participation Sports. Sejong: Ministry of Culture, Sports and Tourism.

Ministry of Culture, Sports and Tourism. (2017). 2017 National Survey on Participation Sports. Sejong: Ministry of Culture, Sports and Tourism.

Mosston, M., \& Ashworth, S. (2002). Teaching Physical Education (5th ed.). New York: Benjamin Cummings.

Oh, J. H. (2000). The Effect of Sports Participations on View of Sports Values and Attitude on University Students. Korean Journal of Physical Education, 39(4), 165-174.

Park, B. J. (2015). Sport Industry and Normative Value of Sport. Philosophy of Movement: The Journal of Korean Philosophic Society for Sport and Dance, 23(3), 55-79.

Park, H. W., \& Na, Y. O. (2013). A study on understanding of gender discrimination and interfering factors to practicing for gender equality in the sport. Philosophy of Movement: Journal of Korean Philosophic Society for Sport and Dance, 21(1), 77-95

Park, I. K., Kim, H. M., \& Park, S. H. (2017). The effect of perceived coaching behavior on athletic satisfaction and burnout. Korean Society of Sport Psychology, 28(1), 59-69.

Park, J. Y., Kim, K. S., \& Kim, T. H. (2015). An inquiry into the meaning of women's experiences of physical activities as lifelong education. Journal of Korean Physical Education Association for Girls and Women, 29(2), 347-369.

Park, S. J. (2018). Theoretical foundation for the ethics of coaching sport. Korean Journal of Sport Science, 29(4), 681-692.

Song, Y. G., Cheon, S. H., \& Hwang, S. H. (2017). Influence of coaching styles on athletes' psychological need 
satisfaction, mental toughness, and burnout in sport context. Korean Journal of Sport Studies, 56(1), 247-261.

Sport England. (2017). Active lives survey 2015-16. London: Sport England.

Stephenson, W. (1953). The study of behavior: Q-technique and its methodology. IL: University of Chicago Press.

Valenta, A. L., \& Wigger, U. (1997). Q-methodology: Definition and application in health care informatics. Journal of the American Medical Informatics Association, 4(6), 501-510.

Watts, S., \& Stenner, P. (2005). Doing Q methodology: Theory, method and interpretation. Qualitative Research in Psychology, 2(1), 67-91.

Wigfield, A., Eccles, J. S., Yoon, K. S., Harold, R. D., Arbreton, A. J., Freedman-Doan, C., \& Blumenfeld, P. C. (1997). Change in children's competence beliefs and subjective task values across the elementary school years:
A 3-year study. Journal of Educational Psychology, 89(3), 451.

Williams, G. C., \& Deci, E. L. (1996). Internalization of biopsychosocial values by medical students: a test of self-determination theory. Journal of Personality and Social Psychology, 70(4), 767.

Yoo, Y. J., Kim, J. H., \& Hwang, D. H. (2017). The effects of football coach's coaching language to football player's trust of coach and sport confidence. Journal of Coaching Development, 19(3), 30-38.

You, J. A. (2007). Understanding the educational meanings and orientations of physical activity as the essence and tool of physical education content. The Journal of Curriculum and Evaluation, 10(1), 253-272.

Youth Sport Trust. (2000). Sports colleges: The first two years: Innovation in physical education and sport. London: The Stationer Office.

\title{
여성 생활체육 참여자의 코칭 경험에 대한 주관성 연구: $\mathrm{Q}$ 방법론적 접근
}

\author{
명왕성 ${ }^{1}$, 박광호 ${ }^{2}$ \\ ${ }^{1}$ 한신대학교 조교수 \\ 2연세대학교 강사
}

[목적] 본 연구는 여성 생활체육 참여자의 코칭 경험에 대한 주관성(수용인식 및 선호유형)을 유형화하는데 그 목적이 있다. [방법] 이를 위해 Q방법론을 분석 틀로 채택하였으며, 25 개의 Q-표본과 25명의 P-표본을 분석에 활용하였다. 자료처리는 PQmethod를 사용하였다. [결과] 그 결과, 소통-인성 중시형(I), 기능-몰입 지향형(II), 과정-흥미 중시형(III), 기능-포괄 지향형(IV)으로 유형화되었으며, '비기능적 가치 지향형(I, III)'과 '기능적 가치 지향형(II, IV)'으로 범주화하여 학술적 및 실용적 의의를 도출하였다. [결론] 본 연구는 코칭 경 험뿐만 아니라 여성 참여자가 스포츠를 바라보는 관점, 스포츠 참여로부터 기대하는 가치와 규범을 탐색하는 데에도 노력을 기울였으며, 이는 여성 스포츠에 관한 사회·심리학적, 철학적 논의에 있어 다양한 관점을 제공 하였다. 또한, 각 유형과 그 특성은 여성 스포츠 현장의 교수법(코칭론)에 있어 유의미한 기초 자료로 활용할 수 있다.

주요어: 생활체육, 여성스포츠, 코칭, 주관성, Q방법론 